\title{
The blood sucking on human by Placobdella costata (O. F. Müller, 1846) (Hirudinida: Glossiphoniidae) - case study with notes on body form
}

Joanna Cichocka ${ }^{1}$, Aleksander Bielecki ${ }^{2}$, Izabela Jablonska-Barna ${ }^{3}$, Łukasz Krajewski ${ }^{4}$, Katarzyna Topolska ${ }^{5}$, Joanna Hildebrand ${ }^{6}$, Małgorzata Dmitryjuk ${ }^{3}$, Anna Biedunkiewicz ${ }^{3}$, and Andrei Abramchuk ${ }^{7}$

${ }^{1}$ High School in Olsztyn

${ }^{2}$ University of Warmia and Mazury in Olsztyn Faculty of Biology and Biotechnology

${ }^{3}$ University of Warmia and Mazury in Olsztyn

${ }^{4}$ Wetland Protection Center

5 independent scientist

${ }^{6}$ University of Wrocław

${ }^{7}$ Birdlife Belarus

January 6, 2021

\begin{abstract}
Abstract: 1. In our paper four events of blood sucking on human by Placobdella costata were described. 2. Human blood was sucked by both adults and juvenile specimens of P. costata. 3. The feeding strategies of juveniles under parental care are presented. 4. New data of juvenile specimens body form are presented. 5. Information on the potential role of mammals in species dispersion and habitat preferences of leeches are under consideration.
\end{abstract}




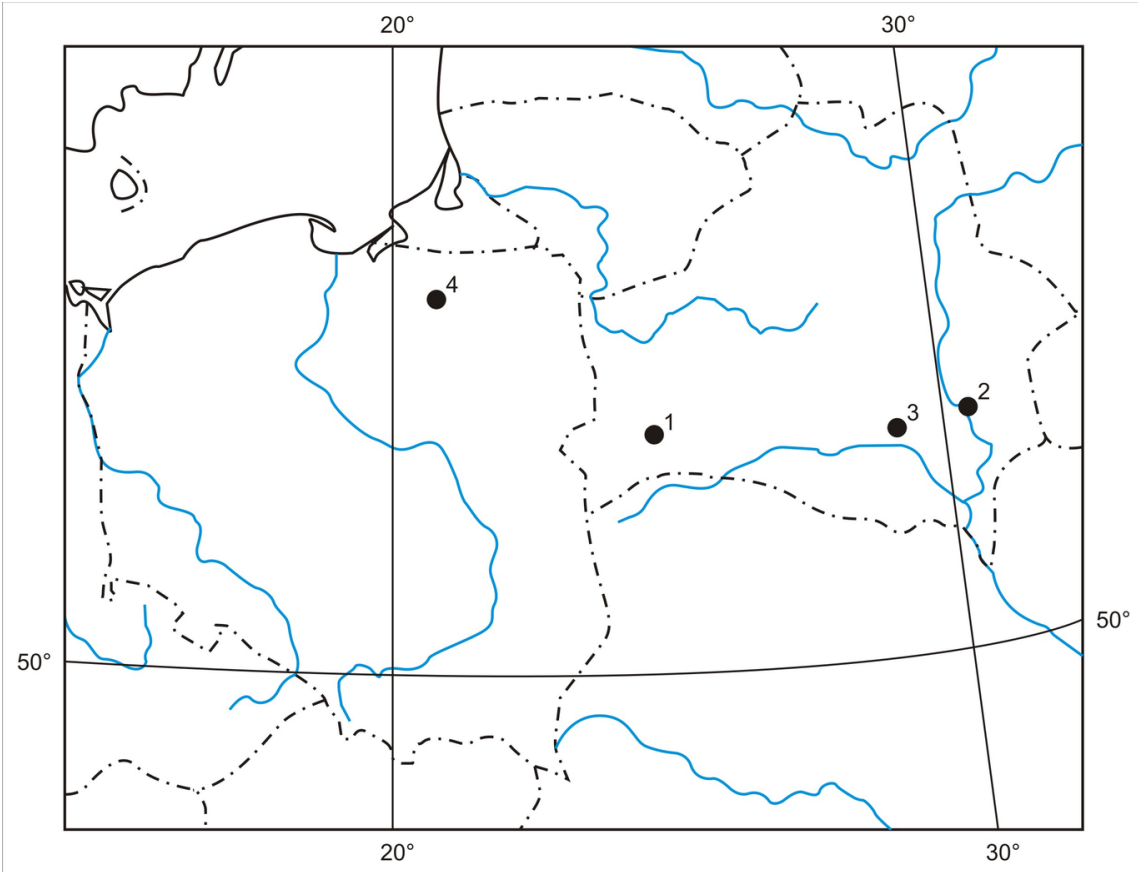




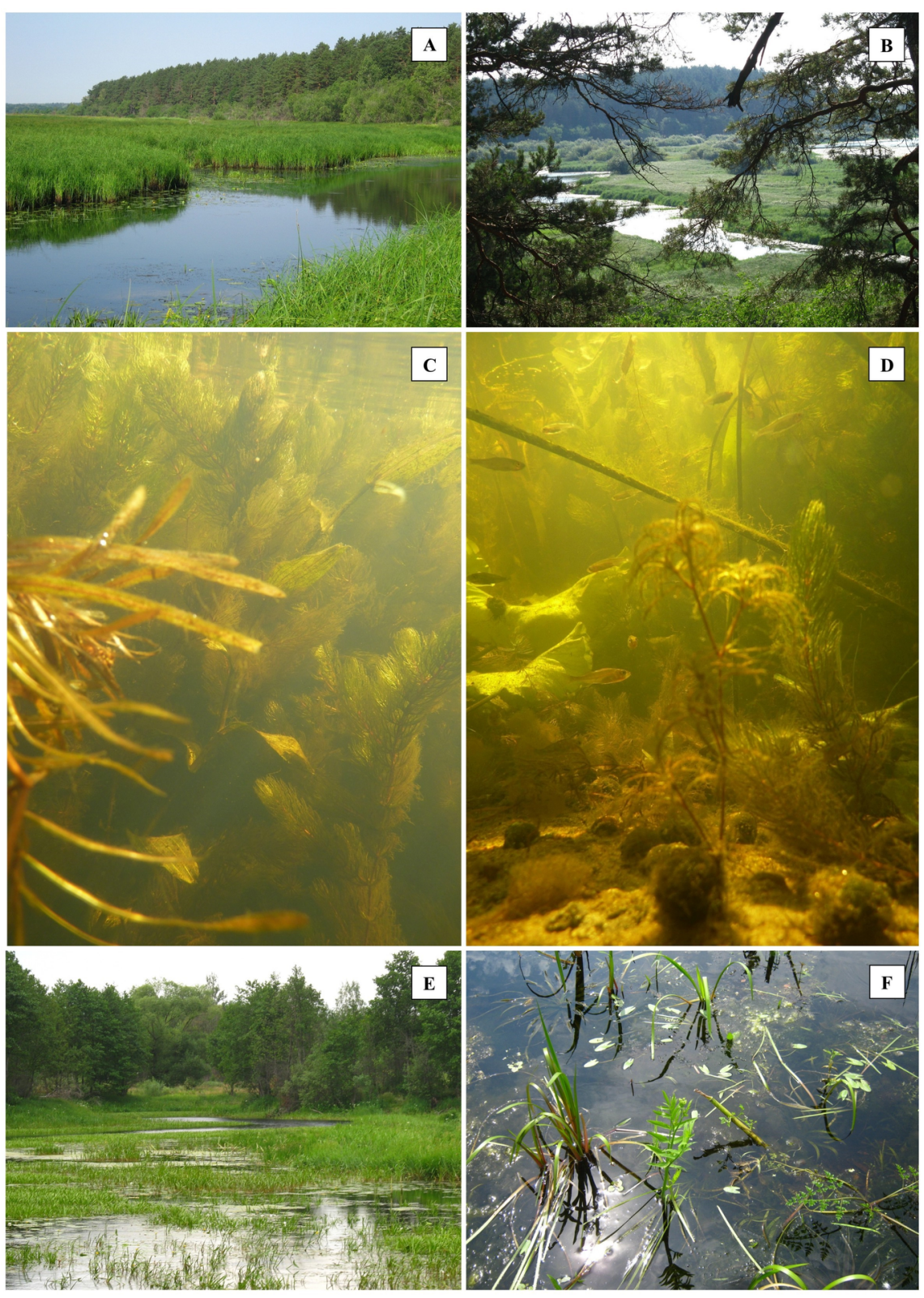



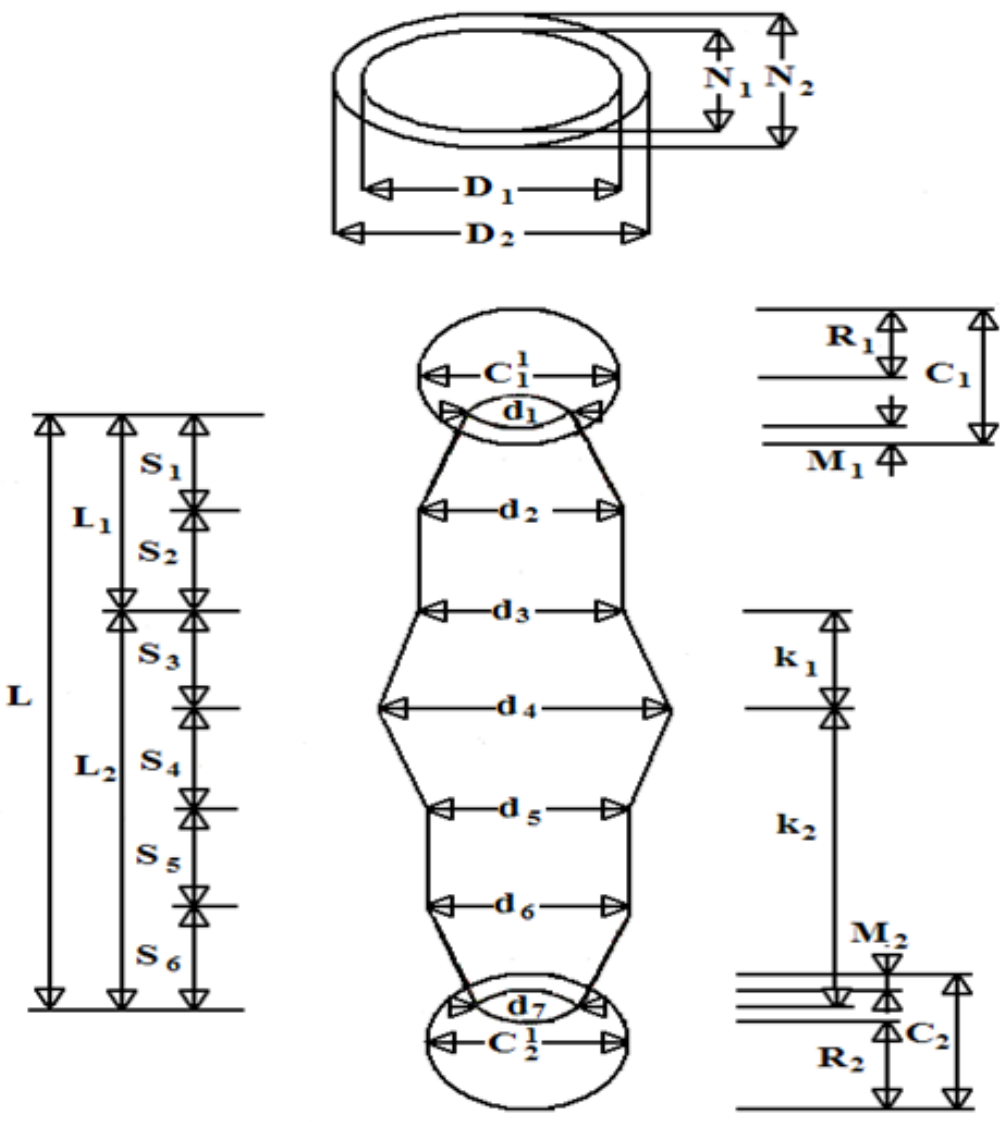

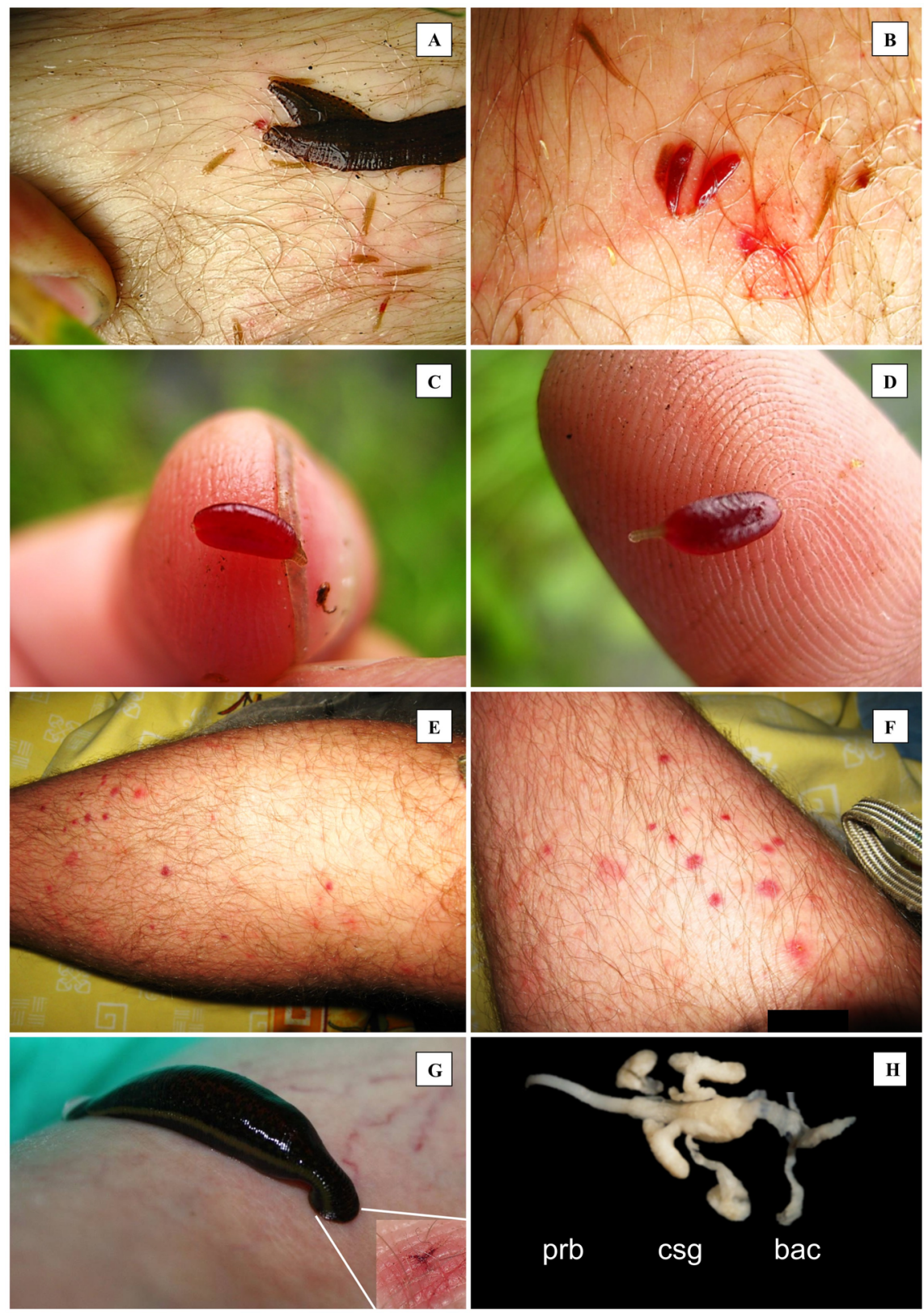

\section{Hosted file}

Fig. 5.pdf available at https://authorea.com/users/387718/articles/502667-the-blood-suckingon-human-by-placobdella-costata-o-f-m\%C3\%BCller-1846-hirudinida-glossiphoniidae-casestudy-with-notes-on-body-form 